\section{EFFECT OF THIOCYANATE ON BASAL BLOOD PRESSURE}

BY

\section{K. SEVERIN ALSTAD, M.D., M.R.C.P.}

(From the Department of Medicine, University of Otago, New Zealand)

Many conflicting views have been published since thiocyanates were first administered therapeutically at the beginning of this century; and although Hines (1946) and Watkinson and Evans (1947) stated that these are the only drugs capable of satisfactory use in the treatment of hypertensive disease, many are not convinced of their action. For example, Ayman (1930, 1931) endeavoured to show that their effect was not greater than that of placebos, basing his criteria of action mainly on symptomatic improvement and not so much on pressure changes. Evans and Loughnan (1939) investigated a large number of substances credited with lowering blood pressure and found that most of them, including thiocyanates, were without greater effect than placebos administered for a similar period; the results were based on periods of treatment lasting only two to three weeks. Those who hold similar opinions may find support for their belief in the excellent review by Foster (1943) in which he states that in an extensive search of the literature he had been unable to find evidence of the hypotensive effect of thiocyanates in animals, short of a toxic dose.

There have been, however, a number of careful investigations (Daley et al., 1943 ; Beamish and Adamson, 1945 ; Watkinson and Evans, 1947) in which every precaution was taken to control and standardize conditions and in which it would seem that thiocyanates did produce significant falls in the systolic and diastolic blood pressures.

At Otago University Medical School special interest has centred round the question of hypertensive disease, and the importance of what have been called the casual, basal, and supplemental blood pressures has been emphasized (Alam et al., 1943). By "casual" is meant that pressure recorded under ordinary clinical conditions of examination. In the particular study to which reference is made below, the casual pressure was estimated after a few minutes' rest, usually in the recumbent position. "Basal," on the other hand, refers to pressures taken after due precautions have been instituted to remove the influence of stimuli, both extrinsic and intrinsic. Basal conditions have been recognized here as being satisfied only when the patient-to whom the whole procedure has been explained beforehand-after a peaceful sleep under the influence of a mild sedative, has become habituated to his surroundings and may be justifiably regarded as in a state of basal metabolism. The "supplemental " pressure -an independent variable-is the difference between the
KEY

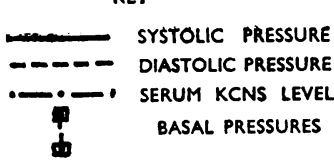
casual and the basal pressures and represents the part of the casual pressure which reflects the physical, emotional, and metabolic activity of the patient at the time of measurement.

The basal pressure has been shown (Smirk, 1944 ; J. A. Kilpatrick, unpublished communication) to be comparatively stable in hypertensive disease, and I have been interested in the examination of the effect of thiocyanate in patients whose basal pressures were measured periodically throughout treatment, controlling the results against treatment with placebos in most of the cases. In the 20 patients investigated so far the preliminary observations indicate a fall in the basal and supplemental pressures, and I feel that the following case note will be of interest. It is put forward as a preliminary account of the whole series will be forthcoming shortly.

\section{Case Report}

The patient, a man aged 74 , of rather stolid type with sluggish cerebration, was admitted to Dunedin Hospital on Aug. 29, 1946, complaining of weakness of the right face, arm, and leg for two days. The onset of the weakness coincided with an attack of giddiness. He had no history of fits, no loss of consciousness, no visual disturbances, and no pain, and had not previously experienced any similar weakness.

On examination he was in a slightly confused state, his speech was thick and slow, and he showed a slight weakness of the right face, arm, and leg. The tendon reflexes were present and 
equal, the superficial reflexes were normal save for the plantar responses, which were extensor in type on both sides.

The cardiovascular system showed little abnormality for a man of his years; there was no evidence of congestive failure, the pulse was regular except for an occasional extrasystole, and the blood pressure was $190 / 110 \mathrm{~mm}$. Hg. Radiography confirmed the clinical findings concerning the size of the heart, and revealed it to be of a shape usually associated with hypertension. The basal blood pressure at this time was $128 / 84 \mathrm{~mm}$. Kidney-function tests were normal, and examination of the other systems showed no evidence of gross pathological change. Improvement was complete in the course of four weeks, and a diagnosis of essential hypertension of a labile variety with encephalopathy was made.

In January, 1947, when the symptoms and clinical manifestations had completely disappeared, it was decided to treat him with potassium thiocyanate in an attempt to reduce his blood pressure so as to minimize a recurrence of the complication: the accompanying chart shows the course of the treatment. $\mathrm{He}$ maintained high concentrations of the drug with great improvement in his general well-being, but later developed mild diarrhoea as a toxic manifestation and continued on treatment for 10 days without indicating this. The drug was stopped temporarily.

\section{Comment}

Attention was drawn to the following: (a) The casual systolic and diastolic pressures began to fall soon after treatment was instituted. (b) At the end of 17 weeks the casual blood pressure had fallen from $190 / 110$ to $125 / 84$, and the basal from $128 / 84$ to the low figure of $88 / 52$. These reductions represent a response to treatment to the extent of $65 \mathrm{~mm}$. systolic and $26 \mathrm{~mm}$. diastolic in the casual blood pressure, and in the basal of $40 \mathrm{~mm}$. systolic and $32 \mathrm{~mm}$. diastolic. (c) The withdrawal of the drug was followed by a rise of both casual and basal pressures, which two weeks afterwards had returned to the levels found before treatment was begun. (d) On treatment being restarted the casual and basal pressures showed the same tendency to fall again.

\section{Conclusions}

In some patients with essential hypertension treatment with thiocyanate causes a well-marked fall in blood pressure.

The reductions in pressure are due partly to decreases in the basal and partly to decreases in the supplemental pressures.

The falls in basal pressure are good evidence that the effect of adequate thiocyanate therapy is pharmacological and not psychological.

\section{REFERENCES}

Alam, G. M., Smirk, F. H., Gatman, M., and Massif Amin (1943). Brit. Heart J., 5, 152.

Ayman, D. (1930). J. Amer. med. Ass., 95, 246.

(1931) Ibid., 96, 1852, 2091.

Beamish, R. E., and Ádamson, J. D. (1945). Canad. med. Ass. J., 53, 236.

Daley, R. M., Ungerleider, H. E., and Gubner, R. S. (1943). J. Amer. med. Ass., 121, 383.

Evans, W., and Loughnan, O. (1939). Brit. Heart J., 1, 199.

Foster, R. E. (1943). Amer. J. med. Sci., 206, 668.

Hines, E. A. (1946). N. Amer. Clin., 30, 869.

Smirk, F. H. (1944). Brit. Heart J., 6, 176

Watkinson, G., and Evans, G. (1947). British Medical Journal, 1 , 595

The Hon. Secretary of the West Derbyshire Medical Society, Dr. H. Rhys Davies, reports that at a meeting held at Matlock on Jan. 25 the following resolution was passed nem. com.: "That this meeting is of the opinion that the omnipotence of the Minister under the Act in general, and in particular in regard to the power of dismissal without appeal to the courts, is contrary to the interest of the community and justifies the profession in abstaining from the Service."

\section{TREATMENT OF ANGINA PECTORIS BY REDUCTION OF BASAL METABOLISM}

BY

\author{
G. SCHOENEWALD, M.D.Berlin \\ Clinical Assistant, West London Hospital
}

From the therapeutic point of view sufferers from angina can be divided into three types: obese, anaemic, and slim. The first two groups are amenable to treatment by reduction of weight and correction of anaemia respectively. The others can only be given nitroglycerin either to shorten attacks or occasionally to prevent them. These comprise, in my experience, more than half the victims of the disease.

Some fifteen years ago American workers first conceived the idea of reducing the demand upon the failing heart by reducing the oxygen demand of the organism. This was achieved by total surgical removal of the thyroid gland, followed by medication with thyroid extract sufficient to prevent myxoedema but not enough to restore the basal metabolism to normal. A new principle was thereby introduced into cardiological treatment: instead of trying to boost the output of the failing heart, the principle of "load shedding "was substituted. In many cases the results of total thyroidectomy were good, but there are objections to radical surgery in a cardiac invalid, and these, together with the inherent technical difficulties, prevented the method from attaining any great popularity.

Thiouracil and its derivatives have now given the physician the means of suppressing thyroid activity, but rather surprisingly these means have not yet been widely exploited in cardiology. In America, W. Raab (1945) treated a small group of cases of angina, with promising results, and in this country a number of cases of heart failure have been given methylthiouracil (Sharpey-Schafer, 1946).

Three cases of angina treated ambulantly with methylthiouracil are here described. All had typical angina of effort, exhibited electrocardiographic abnormalities corroborating the diagnosis, and suffered from three to six attacks daily in the course of their routine activities. Two had previously had a coronary thrombosis-one four years and one nine months before the start of treatment. Their daily routine was not altered in any way during the treatment. Since it is well known that the effect of methylthiouracil is to reduce basal metabolism and eventually produce myxoedema, no attempt was made to follow up changes in basal metabolism. It was felt that this treatment had two possible end-points: the cessation of angina before the onset of myxoedema, and the onset of myxoedema without amelioration of the angina. Each of these two end-points could be determined by clinical observation and by regular control of weight, without estimations of the basal metabolism.

\section{Case 1}

R. D., a male clerk aged 64 , had no history of previous illness. In March, 1946, he suffered an attack of severe substernal pain lasting for 36 hours. Heart sounds were normal, blood pressure was normal and remained so, and ectopic beats appeared during the first two days. An electrocardiogram taken on the fourth day showed the typical changes of a recent coronary thrombosis. After six weeks' rest in bed he was allowed up, but he did not resume work because of two or three attacks of anginal pain daily on minimal physical effort. A chest film showed considerable enlargement of the heart to the left, with elongated and uncoiled aorta. Methylthiouracil, $0.6 \mathrm{~g}$. daily, was started on Dec. 10, 1946. It was reduced to $0.4 \mathrm{~g}$. daily four weeks later. After ten weeks' medication the patient reported complete cessation of angina, and methylthiouracil was thereupon reduced to $0.1 \mathrm{~g}$. a day. His weight had remained constant throughout this period. 